Relations industrielles

Industrial Relations

\title{
Le code criminel et les unions ouvrières
}

Volume 11, numéro 3, juin 1956

URI : https://id.erudit.org/iderudit/1022627ar

DOI : https://doi.org/10.7202/1022627ar

Aller au sommaire du numéro

\section{Éditeur(s)}

Département des relations industrielles de l’Université Laval

\section{ISSN}

0034-379X (imprimé)

1703-8138 (numérique)

Découvrir la revue

\section{Citer ce document}

(1956). Le code criminel et les unions ouvrières. Relations industrielles / Industrial Relations, 11(3), 217-219. https://doi.org/10.7202/1022627ar
Résumé de l'article

Pour l'intérêt de nos lecteurs, nous avons cru intéressant de reproduire les articles 409, 410, 411, 365, 366 et 367 du code criminel relatifs aux unions ouvrières. C'est un extrait du chapitre 51 des Statuts annuels du Canada, 1953-54.

$1953-54$ 


\section{INFORMATIONS}

\section{LE CODE CRIMINEL ET LES UNIONS OUVRIERES}

Pour l'intérêt de nos lecteurs, nous avons cru intéressant de reproduire les articles 409, 410, 411, 365, 366 et 367 du code criminel relatifs aux unions ouvrières. C'est un extrait du chapitre 51 des Statuts annuels du Canada, 1953-54.

Immunité des syndicats ouvriers contre les complots en vue de restreindre le commerce

409. (1) Un complot en vue de restreindre le commerce est une convention entre deux ou plusieurs personnes pour accomplir ou faire accomplir un acte illégal destiné à restreindre le commerce.

(2) Les objets d'un syndicat ouvrier ne sont pas illégaux au sens du paragraphe (1) pour la seule raison qu'ils restreignent le commerce.

410. (1) Nul ne doit être déclaré coupable de l'infraction de complot, du seul fait qu'il

a) refuse de travailler avec un ouvrier ou pour un patron; ou

b) qu'il accomplit un acte ou fait accomplir un acte aux fins d'une entente industrielle ou coalition industrielle, à moins que cet acte ne constitue une infraction expressément punissable par la loi.

(2) $\mathrm{Au}$ présent article, l'expression «entente industrielle» ou «coalition industrielle 》 (trade combination) signifie toute entente entre patrons ou ouvriers ou d'autres personnes pour réglementer ou changer les rapports entre patrons ou ouvriers ou la conduite d'un patron dans ses affaires ou d'un ouvrier dans son emploi ou contrat de travail ou service, ou concernant ces affaires, emploi, contrat de travail ou service.

411. (1) Est coupable d'un acte criminel et passible d'un emprisonnement de deux ans, quiconque complote, se coalise, se concerte ou s'entend avec un autre.

a) pour limiter indûment les facilités de transport, de production, de fabrication, de fourniture, d'emmagasinage ou de commerce d'un article quelconque;

b) pour restreindre ou léser l'industrie ou le commerce à l'égard d'un article;

c) pour empêcher, limiter ou diminuer, indûment, la fabrication ou la production d'un article ou pour en élever déraisonnablement le prix; ou

d) pour prévenir ou diminuer indûment la concurrence dans la production, la fabrication, l'achat, le troc, la vente, le transport ou la fourniture d'un article, ou dans les taux d'assurance sur les personnes ou les biens.

(2) Aux fins du présent article, l'expression «article» signifie un article ou une denrée pouvant faire l'objet d'une industrie ou d'un commerce.

(3) Le présent article ne s'applique pas aux associations d'ouvriers ou d'employés formées pour leur propre protection raisonnable en qualité d'ouvriers ou d'employés. 


\section{II}

\section{Violation de contrat, intimidation et piquetage Distinction injuste envers les syndiqués}

365. (1) Quiconque, volontairement, viole un contrat, sachant ou ayant un motif raisonnable de croire que les conséquences probables de son acte, qu'il agisse seul ou en liaison avec d'autres, seront

a) de mettre en danger la vie humaine;

b) d'infliger des blessures corporelles graves;

c) d'exposer des biens de valeur, immeubles ou réels, ou meubles ou personnels, à une ruine totale ou à de graves dommages;

d) de priver les habitants d'une cité ou localité, ou de quelque partie d'une cité ou localité, totalement ou dans une grande mesure, de leur approvisionnement de lumière, d'énergie, de gaz ou d'eau; ou

e) de retarder ou d'empêcher le service d'une locomotive, d'un tender, d'un convoi ou wagon de marchandises ou de voyageurs sur un chemin de fer qui est un voiturier public, est coupable

f) d'un acte criminel et passible d'une emprisonnement de cinq ans, ou

g) d'une infraction punissable sur déclaration sommaire de culpabilité. le seul fait.

(2) Nul ne viole volontairement un contrat au sens du paragraphe (1) par

a) que, étant au service d'un employeur, il cesse de travailler par suite du défaut, de la part de son employeur et de lui-même, de s'entendre sur une question quelconque touchant son emploi, ou

b) que, ètant membre d'une organisation d'employés formée en vue de régler les relations entre employeurs et employés, il cesse de travailler par suite du défaut, de la part de l'employeur et d'un agent négociateur agissant au nom de l'organisation, de s'entendre sur une question quelconque touchant l'emploi de membres de l'organisation,

si, avant la cessation du travail, toutes les mesures prévues par la loi quant au règlement de conflits industriels sont prises et si toute disposition en vue du règlement définitif de différends, sans cessation du travail, contenue ou, par la loi, censée contenue dans une convention collective, est observée et exécutée.

(3) Aucune procédure ne doit être intentée sous le régime du présent article sans le consentement du procureur général.

366. (1) Est coupable d'une infraction punissable sur déclaration sommaire de culpabilité, quiconque, injustement et sans autorisation légitime, dans le dessein de forcer une autre personne à s'abstenir de faire une chose qu'elle a légalement le droit de faire, ou à faire une chose qu'elle peut légalement s'abstenir de faire.

a) use de violence ou de menaces de violence envers cette personne, ou envers sa femme ou ses enfants, ou endommage ses biens;

b) intimide ou tente d'intimider cette personne ou un parent de cette personne par des menaces de violence ou d'un autre mal, ou de quelque peine, à elle ou à l'un de ses parents, ou de dommage aux biens de l'un quelconque d'entre eux, au Canada ou ailleurs;

c) suit avec persistance cette personne de place en place;

d) cache des outils, vêtements ou autres biens, possédés ou employés par cette personne, ou l'en prive ou fait obstacle à l'usage qu'elle en fait;

e) avec un ou plusieurs autres, suit désordonnément cette personne sur une grande route;

f) cerne ou surveille la maison d'habitation ou le lieu où cette personne réside, travaille, exerce son entreprise ou se trouve; ou

g) bloque ou obstrue une grande route. 
(2) Ne surveille ni ne cerne, au sens du présent article, celui qui est présent à ou près une maison d'habitation ou un lieu, ou s'en approche, à seule fin d'obtenir ou de communiquer des renseignements.

367. Est coupable d'une infraction punissable sur déclaration sommaire de culpabilité, quiconque, étant un employeur ou l'agent d'un employeur, injustement et sans autorisation légitime,

a) refuse d'employer ou congédie une personne pour la seule raison que ladite personne est membre d'un syndicat ouvrier légitime ou d'une association ou d'une association ou alliance légitime d'ouvriers ou d'employés formée pour l'avancement licite de leurs intérêts et organisée pour les protéger dans la réglementation des salaires et des conditions de travail;

b) cherche par l'intimidation, par la menace de la perte d'une situation ou d'un emploi, ou en causant la perte réelle d'une situation ou d'un emploi, ou par la menace ou l'imposition d'une peine pécuniaire, à contraindre des travailleurs ou employés de s'abstenir d'être membres d'un syndicat ouvrier ou d'une association ou alliance à laquelle ils ont légitimement droit d'appartenir; ou

c) complote, se coalise, conclut une convention ou s'entend avec un autre employeur ou son agent pour accomplir l'un des actes mentionnés à l'alinéa a) ou b).

\section{LE CONGRES DU TRAVAIL CANADIEN}

Le ministre du Travail, l'hon. Milton F. Gregg, a annoncé récemment que l'effectif des syndicats ouvriers du Canada s'établit présentement à $1,346,000$ membres. La statistique préliminaire, basée sur un relevé effectué par la Division de l'économique et de recherches du ministère du Travail, indique au ler janvier 1956 une hausse de 6 p. 100 de l'effectif syndical au regard de l'année précédente.

Durant la dernière année de leur existence distincte, le Congrès des Métiers et du Travail du Canada et le Congrès canadien du Travail ont vu s'accroître leur effectif de 6.5 et 4.6 p. 100 respectivement. En conséquence, l'effectif représenté à la réunion de fondation du Congrès du Travail canadien, laquelle a eu lieu à Toronto au cours d'avril, s'établit à environ 1,018,000 membres.

Le total estimatif des membres de chacun des congrès et des organisations indépendantes s'établit comme suit:

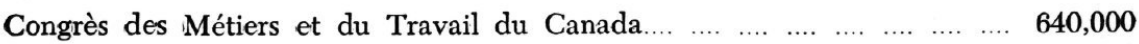

Congrès canadien du Travail.... ................................................ 378,000

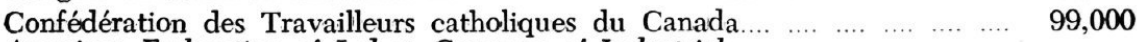

American Federation of Labor, Congress of Industrial

$\begin{array}{llllllllllllllll}\text { Organisations } & \text { seulement... } & \ldots . & \ldots & \ldots . & \ldots . & \ldots . & \ldots . & \ldots & \ldots & \ldots . & \ldots . & \ldots . & \ldots . & 1,000\end{array}$

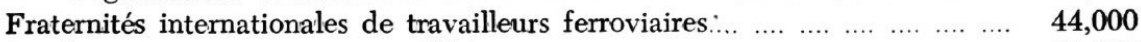

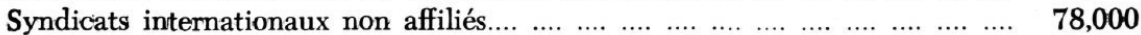

Organisations nationales, régionales et locales non affiliées................. 106,000

$\overline{1,346,000}$

* Ce texte a été fourni par le Service d'Information, Ministère du Travail, Ottawa. 